\title{
Erratum to: Light Metals 2018
}

\author{
Olivier Martin
}

\section{Erratum to: \\ O. Martin (ed.), Light Metals 2018, The Minerals, Metals \& Materials Series, https://doi.org/10.1007/978-3-319-72284-9}

In Chapters "Effects of Rare Earth Er Additions on Microstructure and Mechanical Properties of an Al-Zn-Mg$\mathrm{Cu}$ Alloy" and "Effects of Extrusion and Heat Treatment Conditions on Microstructure and Mechanical Properties of an $\mathrm{Al}-\mathrm{Zn}-\mathrm{Mg}-\mathrm{Cu}-\mathrm{Er}$ Alloy" the author affiliations were not associated with the proper authors.

- S. Kord and P. G. Koppad are affiliated with the correct addresses.

- M. Alipour is affiliated with addresses "Department of Biomaterial, Pasteur Institute of Iran, Tehran, Iran” and "Department of Materials Science and Engineering,
University of Tabriz, Tabriz, Iran" but should be affiliated with "Faculty of Materials Science and Engineering, K. N. Toosi University of Technology, Tehran, Iran" and "Department of Materials Science and Engineering, University of Tabriz, Tabriz, Iran".

- M. H. Siadati is affiliated with "Department of Biomaterial, Pasteur Institute of Iran, Tehran, Iran" but should be affiliated with "Faculty of Materials Science and Engineering, K. N. Toosi University of Technology, Tehran, Iran".

- M. Kord is affiliated with "Faculty of Materials Science and Engineering, K. N. Toosi University of Technology, Tehran, Iran" but should be affiliated with "Department of Biomaterial, Pasteur Institute of Iran, Tehran, Iran”.

The erratum book has been updated with the changes.

The updated online version of these chapters can be found at https://doi.org/10.1007/978-3-319-72284-9_60 https://doi.org/10.1007/978-3-319-72284-9_61 https://doi.org/10.1007/978-3-319-72284-9 